\title{
Pengaruh Natural Aging Terhadap Sifat Mekanis Aluminium Paduan A356 Sebagai Bahan Propeler
}

\author{
Suyanto $^{1 *}$, Ratna Dwi Kurniawan ${ }^{1}$, Padang Yanuar ${ }^{2}$ \\ ${ }^{1}$ Program Studi Bangunan Kapal, Universitas IVET \\ Jl. Pawiyatan luhur IV, No. 7, bendan dhuwur, Semarang \\ ${ }^{2}$ Jurusan Teknik Mesin, Politeknik Negeri Semarang \\ Jl. Prof. Sudharto, S.H., Tembalang, Semarang \\ *E-mail: suyantoeste@yahoo.com
}

Diterima: 04-12-2019; Direvisi: 16-12-2019; Dipublikasi: 31-12-2019

\begin{abstract}
Abstrak
Aluminium A356 sebagai bahan pengecoran propeler masih mempunyai kekuatan yang rendah dan bersifat getas. Penelitian dilakukan untuk mengetahui pengaruh natural aging pada temperatur ruang terhadap kekerasan dan kekuatan aluminium paduan A356. Waktu aging pada temperatur ruang divariasikan mulai 1 hingga 20 hari. Pengujian yang dilakukan adalah uji komposisi, uji tarik, dan uji kekerasan. Nilai kekuatan tarik optimum dicapai setelah natural aging 10 hari, dengan nilai 183,6 MPa. Nilai keuletan material turun seiring dengan bertambahnya waktu natural aging. Nilai kekerasan meningkat seiring dengan bertambahnya waktu aging, dan mencapai kekerasan optimum setelah aging 6 hari dengan nilai kekerasan 94 BHN.
\end{abstract}

Kata kunci: Aluminium; A356; natural aging

\begin{abstract}
A356 aluminum alloy as a propeller casting material still has low strength and brittle. The study was conducted to determine the effect of natural aging on the hardness and strength of A356 aluminum alloy. The natural aging time varies from 1 to 20 days. Composition, tensile, and hardness tests are considered for mechanical properties study. Results show that the optimum tensile strength value is achieved after 10 days of natural aging, with a value of 183.6 $M P a$. The toughness of the material decreases with increasing natural aging time. The hardness increases with aging time, and reaches optimum value after 6 days aging, with a value of 94 BHN.
\end{abstract}

Keywords: Aluminum; A356; natural aging

\section{Pendahuluan}

Aluminium merupakan jenis logam terbanyak kedua yang digunakan setelah baja. Hal tersebut dikarenakan aluminium memiliki beberapa kelebihan, diantaranya adalah bobotnya yang ringan dan tahan terhadap korosi. Namun untuk aplikasi tertentu terutama aluminium murni terlalu lunak, sehingga kekuatan dan kekerasannya perlu ditingkatkan. Laku panas dan memadu aluminium murni dengan unsur pemadu merupakan dua cara yang bisa diterapkan untuk mengeraskan dan menguatkan aluminium murni. Perlakuan panas yang dikenakan pada aluminium bertujuan untuk menghasilkan ukuran butri yang lebih halus, serta memacu pembentukan precipitat yang berguna dalam menghambat dislokasi. Sementara itu untuk aluminium murni tidak efektif jika dikenakan laku panas, karena tidak mempunyai unsur pembentuk percipitat. Sehingga cara yang efektik untuk meningkatkan sifat mekanik aluminium murni adalah dengan cara memadunya dengan unsur lain [1].

Industri pengecoran propeler kapal tradisional dengan bahan aluminium banya dijumpai di daerah Pati. Aluminium yang digunakan adalah jenis A356. Pertimbangan penggunaan aluminium jenis ini karena kekuatan dan mampu tuangnya yang baik. Penelitian terhadap sifat mekanik hasil pengecoran propeler berbahan aluminium pernah dilakukan, dan diketahui bahwa kekuatan tariknya masih rendah. Uji tarik menunjukkan kekuatan tarik hasil pengecoran propeler berbahan A356 sebesar 139,2 MPa, lebih rendah dari kekuatan tarik A356 standar yaitu sebesar $172 \mathrm{MPa}$. Sifat hasil pengecoran yang getas ditandai dengan nilai regangan yang hanya 2,48\% [2]. 
Suyanto, dkk. / Jurnal Rekayasa Mesin p-ISSN: 1411-6863, e-ISSN: 2540-7678 Vol.14|No.3|97-103| Desember|2019

A356 merupakan aluminium paduan dengan unsur pemadu utama Si dan Mg. Proses perlakuan panas bisa dipilih sebagai cara untuk meningkatkan sifat mekanis logam tersebut. Jenis laku panas yang bisa dipilih dalam peningkatan kekuatan aluminium paduan adalah dengan proses aging atau age hardening. Proses age hardening melalui beberapa tahap yaitu yang pertama adalah solution heat teratmen, yang ke dua adalah quenching, dan yang ke tiga adalah aging [3].

Solutioning adalah proses mempertahankan suhu aluminium pada suhu sedikit di bawah suhu eutectic. Dengan proses ini precipitat yang ada akan larut dan membentuk larutan padat atau solid solution yang homogen dalam fase $\alpha$. Quenching adalah proses pendinginan secara cepat. Proses ini dilakukan dengan mencelupkan material ke dalam cairan pendingin berupa minyak atau air. Proses ini dilakukan untuk membentuk larutan padat yang sangat jenuh atau super saturated solid solution. Proses terakhir adalah penuaan atau aging. Proses ini dilakukan dengan menahan material pada suhu aging secara konstan selama waktu tertentu. Proses ini dilakukan untuk mencapai terbentuknya precipitat baru. Precipitat yang diharapkan adalah memiliki ukuran dan sebaran yang homogen. Sifat mekanik bahan akan meningkat dipengaruhi oleh terbentuknya precipitat tersebut.

Terdapat dua jenis proses aging, yaitu artificial aging dan natural anging. Artificial aging adalah menahan panduan aluminium pada suhu tertentu, semisal menahan pada suhu $150{ }^{\circ} \mathrm{C}$ selama 4 jam, atau pada suhu $200{ }^{\circ} \mathrm{C}$ selama 2 jam [4]. Natural aging adalah proses penuaan atau menahan material pada suhu ruangan dalam jangka waktu tertentu. Natural aging hanya bisa menghasilkan cluster atau pengelompokan dari elemen paduan terlarut. Semisal yang terjadi pada paduan aluminium AW-6060, cluster yang terbentuk adalah Mg dan $\mathrm{Si}$. Cluster yang terbentuk ini akan berpengaruh pada peningkatan sifat mekanis [5].

Proses natural aging bisa berefek positif dan negatif pada sifat mekanik material. Proses aging pada aluminium paduan rendah menghasilkan efek positif, dimana sifat mekanik paduan aluminium akan meningkat setelah mengalami natural aging selama waktu tertentu [6]. Efek negatif dari proses aging biasanya terjadi jika proses aging dikenakan pada aluminium paduan tinggi. Aluminium jenis ini biasanya diaplikasikan pada bidang otomotif dan konstruksi [3].

Beberapa penelitian tentang natural aging telah dilakukan untuk peningkatan sifat mekanik paduan aluminium. Shwe, dkk [4] menggunakan bahan aluminium paduan A17075, solution treatmen pada suhu $460{ }^{\circ} \mathrm{C}$ selama 20 jam, dilanjutkan quenching dengan air. Kekerasan awal sebelum megalami natural aging adalah 50 HRF, kekerasan setelah aging 10 hari adalah $85 \mathrm{HRF}$ atau meningkat 70\% dibanding kekerasan sebelum natural aging. Tafti dkk [7] melakukan penelitian terkait natural aging, menggunakan material aluminium paduan Al 2024. Solution treatmen dilakukan pada suhu $493^{\circ} \mathrm{C}$ selama 30 menit, dan quenching dengan air. Natural aging dilakukan selama 0,5 jam, 1,5 jam, 4 jam, dan 24 jam. Selama proses aging sifat mekanik naik dengan perlahan. Pada aging 4 jam nilai kekerasan naik $94 \%$, kekuatan naik $23 \%$, dan elongation turun 14\%. Haris dan Tri Iswanto melakukan penelitian tentang pengaruh natural dan artificial aging terhadap sifat fisis dan mekanis velg berbahan aluminium A356 [12]. Hasil penelitian menunjukkan bahwa proses perlakuan natural aging dapat meningkatkan sifat mekanis hasil coran pada centrifugal casting, dan dapat menjadi pilihan dengan biaya yang lebih efisien dibandingkan artificial aging.

Penelitian ini dilakukan sebagai tindak lanjut penelitian terdahulu, yaitu penelitian terhadap sifat mekanis hasil pengecoran propeler berbahan aluminium A356 as cast, yang menunjukkan sifat getas dan kekuatan tarik rendah [2]. Untuk meningkatkan kekuatan, keuletan, dan kekerasan propeler dipilih treatmen menggunakan natural aging karena biaya lebih efisien dibandingkan artificial aging [12]. Natural aging juga efektif menaikkan kekerasan, kekuatan, dan keuletan bahan aluminium paduan [7].

Penelitian ini bertujuan untuk mengetahui pengaruh proses natural aging terhadap sifat mekanis paduan aluminium A356 sebagai bahan propeler kapal tradisional, dengan variasi waktu aging. 
Suyanto,dkk. / Jurnal Rekayasa Mesin

p-ISSN: 1411-6863, e-ISSN: 2540-7678

Vol.14|No.3|97-103| Desember|2019

\section{Metode penelitian}

\subsection{Pengecoran propeler}

Proses pengecoran propeler menggunakan bahan aluminium ingot yang siap pakai. Ingot dicairkan dalam tungku peleburan hingga mencapai suhu 630C. Kemudian dituang ke dalam cetakan propeler dengan bahan cetakan pasir. Setelah dingin, propeler dikeluarkan dari cetakan, kemudian dibuat spesimen uji kekerasan, uji tarik, dan uji komposisi. Sepesimen dibuat dari bagian daun propeler.

\subsection{Perlakuan panas}

Proses laku panas dilakukan di Laboratorium Metalurgi Unwahas. Laku panas yang dikenakan adalah T4 dengan urutan sebagai berikut:

1) Solutioning, dengan menahan material di bawah suhu eutectic 540C dalam waktu 1 jam, bertujuan untuk melarutkan precipitat yang ada. Fasa yang terbentuk dari proses ini adalah solid solution yang homogen dalam bentuk fase $\alpha$.

2) Quenching, adalah pendinginan cepat yang dilakukan dengan mencelupkan material ke dalam air pendingin pada suhu kamar . Proses ini diharapkan akan membentuk super saturated solid solution.

3) Natural Aging, dilakukan dengan mempertahankan material pada suhu kamar. Selanjutnya dilakukan pengujian sifat mekanis. Uji sifat mekanis dilakukan pada material sesaat setelah quenching, serta pengujian pada waktu aging 1, 2, 4, 6,8,10, dan 20 hari.

\subsection{Uji komposisi}

Komposisi kimia paduan aluminium sebagai bahan propeler diperoleh dengan Uji Komposisi. Pengujian komposisi dilakukan di Laboratorium Metalurgi Politeknik Manufaktur Ceper Klaten, dengan menggunakan alat uji Spectrometer. Pengujian komposisi dilakukan dengan spesimen berketebalan $2 \mathrm{~cm}$. Ketebalan spesimen dibuat cukup untuk menghindari efek terbakar ketika melakukan pengujian dengan Spectrometer.

\subsection{Uji tarik}

Pengujian tarik dilakukan untuk mendapatkan data kekuatan dan keuletan material. Pengujian tarik dilakukan di Laboratorium Material Teknik Unwahas, menggunakan spesimen dengan panjang ukur 25mm, lebar $6 \mathrm{~mm}$, dan tebal 3mm. Standar yang digunakan dalam pengujian tarik adalah ASTM E-8M. Masing-masing variasi waktu natural aging diwakili oleh tiga spesimen uji tarik. Data hasil uji tarik diantaranya adalah kekuatan tarik dan keuletan (\%EL) diambil dari nilai rata-rata pengujian tiga spesimen tersebut.

\subsection{Uji kekerasan}

Pengujian kekerasan dilakukan untuk mengetahui sifat kekerasan material. Pengujian dilakukan di Laboratorium Material Teknik Unwahas, dengan menggunakan alat uji kekerasan Brinell berstandar ASTM E-10. Penyiapan spesimen dilakukan dengan pemotongan daun propeler, mounting spesimen, dan pengamplasan. Saat uji kekerasan identor dikenakan pada penampang potongan arah melintang.

\section{Hasil dan pembahasan}

\subsection{Uji komposisi}

Hasil uji komposisi menunjukkan unsur-unsur yang terkandung dalam bahan aluminium paduan seperti pada Tabel 1. 
Tabel 1. Komposisi bahan propeler

\begin{tabular}{cccccc}
\hline Unsur & Si & Fe & Cu & Mg & Zn \\
\hline $\begin{array}{c}\text { A356 } \\
\text { as cast }\end{array}$ & 7,48 & 0,58 & 0,12 & 0,42 & 0,46 \\
A356 & & & & \\
Standar ASM & $6,5-7,5$ & 0,6 & - & $0,25-0,45$ & 0,35 \\
\hline
\end{tabular}

Komposisi kimia aluminium A356 hasil pengecoran dan komposisi A356 standar ASM bisa dilihat pada Tabel 1. Komposisi kimia unsur $\mathrm{Si}, \mathrm{Fe}$, dan $\mathrm{Mg}$ antara kedua material tersebut bersesuaian. Sedangkan kandungan $\mathrm{Cu}$ dan $\mathrm{Zn}$ cukup berbeda. Pada aluminium hasil pengecoran terdapat kandungan Cu sebesar 0,12\%. Jika dilihat pada A356 standar ASM tidak dijumpai adanya unsur $\mathrm{Cu}$. Sementara itu kandungan $\mathrm{Zn}$ hasil pengecoran $30 \%$ lebih tinggi dibandingkan kandungan Zn pada A356 standar ASM. Peningkatan kandungan Cu pada paduan aluminium akan berpengaruh pada peningkatan kekerasan bahan melalui proses precipitat hardening [8]. Selain kekerasan yang meningkat, peningkatan unsur $\mathrm{Cu}$ juga akan meingkatkan kekuatan tarik, dan menurunkan keuletan bahan [9]. Adapun pengaruh penambahan unsur $\mathrm{Zn}$ adalah terjadinya peningkatan kekerasan bahan [10].

\subsection{Uji Tarik}

Proses uji tarik dilakukan mengacu pada standar ASTM E-8M. Data yang dihasilkan dari uji tarik berupa kekuatan tarik (MPa) dan keuletan berupa persentase pemanjangan (\%EL) bisa dilihat pada Tabel 2.

Tabel 2. Nilai kekuatan tarik dan keuletan

\begin{tabular}{ccc}
\hline $\begin{array}{c}\text { Waktu Natural Aging } \\
\text { (Hari) }\end{array}$ & $\begin{array}{c}\text { Kekuatan Tarik } \\
(\mathrm{MPa})\end{array}$ & $\begin{array}{c}\text { Keuletan } \\
(\% \mathrm{EL})\end{array}$ \\
\hline 0 & 161,1 & 10,5 \\
1 & 164,6 & 9,8 \\
2 & 165,4 & 9,5 \\
4 & 167,7 & 9,3 \\
6 & 177,5 & 8,9 \\
8 & 181,1 & 8,6 \\
10 & 183,6 & 8,4 \\
\hline
\end{tabular}

Data hasil uji tarik menunjukkan bahwa nilai kekuatan tarik material sesaat setelah dilakukannya quenching adalah 161,1 MPa. Seiring dengan bertambahnya waktu natural aging kekuatannya terus mengalami peningkatan. Peningkatan kekuatan tarik optimum dicapai setelah waktu natural aging 10 hari, yaitu dengan nilai kekuatan tarik 183,6 MPa. Peningkatan kekuatan tarik yang terjadi setelah natural aging 10 hari sebesar 32\%. Kenaikan kekuatan tarik yang terjadi setelah natural aging lebih dari 10 hari tidak menunjukkan kenaikan yang signifikan, dan cenderung tetap. 


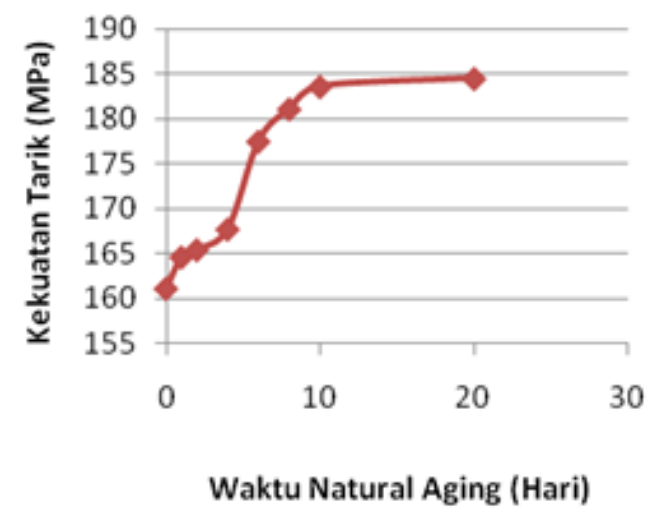

Gambar 1. Nilai Kekuatan tarik material sebagai fungsi dari waktu natural aging

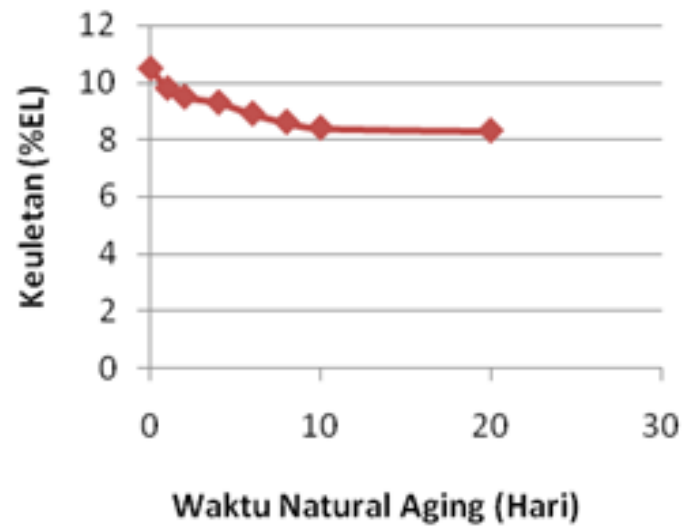

Gambar 2. Nilai keuletan material sebagai fungsi dari waktu aging

Selama mengalami proses natural aging, keuletan material mengalami penurunan seiring bertambahnya waktu aging. Keuletan material sesaat setelah quenching adalah 10,5 \%EL. Penurunan terus terjadi sampai dengan waktu aging 10 hari, dengan nilai keuletan 8,4 \%EL. Nilai keuletan material setelah natural aging lebih dari 10 hari menunjukkan harga yang relatif tetap. Penurunan keuletan yang terjadi setelah 10 hari aging sebesar $20 \%$.

Data sifat mekanis yang dihasilkan melalui uji tarik menunjukkan hasil yang bersesuaian dengan penelitian sebelumnya. Proses aging pada aluminium paduan rendah menghasilkan efek positif, dimana sifat mekanik paduan aluminium akan meningkat setelah mengalami natural aging selama waktu tertentu [6]. Natural aging hanya bisa menghasilkan cluster atau pengelompokan dari elemen paduan terlarut. Cluster yang terbentuk ini akan berpengaruh pada peningkatan sifat mekanis [5].

\subsection{Uji Kekerasan}

Uji kekerasan mengacu pada standar pengujian ASTM E-10 dengan skala kekerasan Brinell. Pengujian kekerasan dilakukan dengan penekanan identor pada tiga titik yang berbeda untuk setiap spesimen. Nilai uji kekerasan rata-rata spesimen dengan variasi waktu natural aging bisa dilihat dalam Tabel 3.

Nilai kekerasan yang diperoleh dari pengujian Brinell pada spesimen yang belum mengalami natural aging menunjukkan harga 83,3 BHN. Nilai kekerasan terus meningkat seiring dengan bertambahnya waktu aging. Nilai kekerasan optimum diperoleh pada waktu aging setelah 6 hari yaitu 94 BHN. Kenaikan kekerasan yang terjadi sebesar 
14\%. Setelah proses aging lebih dari 6 hari, kenaikan nilai kekerasan hanya kecil, dan setelah aging lebih dari 10 hari kekerasan material cenderung tetap.

Tabel 3. Nilai uji kekerasan

\begin{tabular}{ll}
$\begin{array}{c}\text { Waktu Aging } \\
(\text { Jam })\end{array}$ & $\begin{array}{c}\text { Kekerasan } \\
(\text { BHN })\end{array}$ \\
\hline 0 & 83,3 \\
1 & 86,7 \\
4 & 87,7 \\
6 & 93 \\
8 & 94 \\
10 & 94,9 \\
20 & 95,4 \\
\hline
\end{tabular}

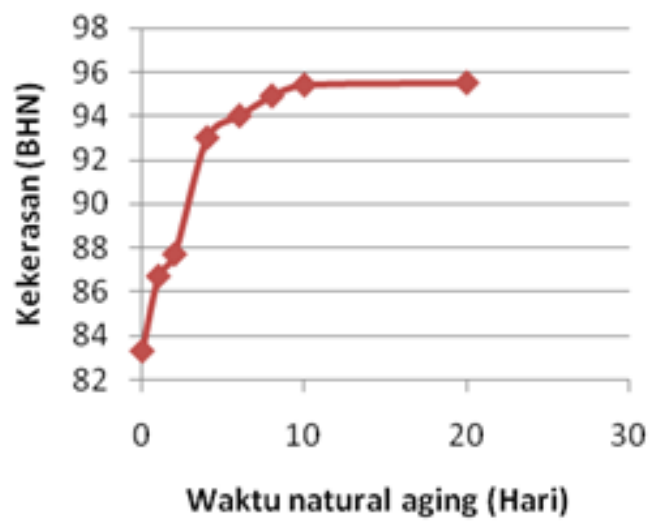

Gambar 3. Nilai kekerasan material sebagai fungsi dari waktu aging

Nilai kekerasan yang diperoleh dari pengujian Brinell pada spesimen yang belum mengalami natural aging menunjukkan harga 83,3 BHN. Nilai kekerasan terus meningkat seiring dengan bertambahnya waktu aging. Nilai kekerasan optimum diperoleh pada waktu aging setelah 6 hari yaitu 94 BHN. Kenaikan kekerasan yang terjadi sebesar 14\%. Setelah proses aging lebih dari 6 hari, kenaikan nilai kekerasan hanya kecil, dan setelah aging lebih dari 10 hari kekerasan material cenderung tetap.

Faktor yang mempengaruhi terjadinya peningkatan nilai kekuatan tarik dan kekerasan bahan adalah terbentuknya precipitat Mg2Si di dalam matrik Al $\alpha$ [11]. Seiring dengan waktu aging, precipitat mengalami perubahan, ukuran dan jumlah precipitat mengalami peningkatan. Ini berpengaruh pada peningkatan kekerasan dan kekuatan [7].

\section{Kesimpulan}

Nilai kekuatan tarik optimum dicapai setelah natural aging 10 hari, dengan nilai 183,6 MPa, atau meningkat 32\% dibanding material yang belum mengalami natural aging. Nilai keuletan material turun seiring dengan bertambahnya waktu natural aging. Nilai keuletan relatif tetap setelah waktu aging lebih dari 10 hari. Nilai kekerasan meningkat seiring 
dengan bertambahnya waktu aging, dan mencapai kekerasan optimum setelah aging 6 hari dengan nilai kekerasan 94 BHN, atau mengalami kenaikan 14\%.

\section{Daftar pustaka}

[1] Meier, M., Heat Treatment of Aluminium Alloys, Department of Chemical Engineering and Materials Science. University of California, Davis (2004).

[2] Suyanto, Syafaat, I., Analisis Sifat Mekanis Propeler Perahu Nelayan Tradisional Berbahan Aluminium, Momentu, Vol. 14, no. 1, pp. 33-38.

[3] Pogatscher, S., Antrekowitsch, H., Leitner, H., Ebner, T., Uggowitzer, P.J., Mechanisms Controlling The Artificial Aging of Al-Mg-Si Alloy, Acta Materialia, Vol. 59 (2011), pp. 3352-3363.

[4] Shwe Wut, H.A., Kay Thi, L.,Waing, K.K., The Effect of Ageing Treatment of Aluminum Alloys for Fuselage Structure-Light Aircraft, World Academy of Science, Engineering and Technology, Vol. 46 (2008), pp. 696-699.

[5] Jin, S., Ngai, T., Zhang, G., Zhai, T., Jia, S., Li, L., Precipitation Strengthening Mechanisms During Natural Ageing and Subsequent Artificial Aging in an Al-Mg-Si-Cu Alloy, Materials Science and Engineering, Vol. 724 (2018), pp. 53-59.

[6] Chang, C., Wieler, I., Wanderka, N., Banhart, J., Positive Effect of Natural pre-ageing on Precipitation Hardening in Al-0.44 at\% Mg-0.38 at\% Si Alloy, Ultramicroscopy, Vol. 109 (2009), pp. 585-92.

[7] Tafti, M.F., Sedighi, M., Hashemi, R., Effects of Natural Aging Treatment on Mechanical, Microstructural and Forming Properties of Al 2024 Aluminum Alloy Sheets, Iranian Journal of Materials Science \& Engineering, Vol. 15, No. 2 (2018), pp. 55-64.

[8] Muzaffer, Z., Erdem, K., Serap, G., Influence of Cu Addition On Microstructure and Hardness of Near-Eutectic Al-Si-xCu-Alloys, Transactions of Nonferrous Metals Society of China, Vol. 21 ((2011), pp. 1698-1702.

[9] Ricardo, A., Gonçalves, Márcio, B., Influence of Copper Content on 6351 Aluminum Alloy Machinability, Procedia Manufacturing, Vol. 1 (2015), pp. 683-695.

[10] Bondan, T.S., Rahmalina, D., Eddy, S., Siradj, Hery, M., Pengaruh Penambahan Unsur Paduan Zn Terhadap Kinerja Balistik Komposit Matriks Al-Zn-6Mg Berpenguat Partikel Silikon Karbida, Prosiding INSINAS 2012-1019, HK141-145.

[11] Ridvan, G., Serhat, A., Alptekin, K., Kerem, A.G., Ahmet, K., Influence of T6 Heat Treatment on A356 and A380 Aluminium Alloys Manufactured by ThixoForging Combined with Low Superheat Casting, Trans. Nonferrous Met. Soc. China, vol. 28 (2018), pp. 385-392.

[12] Haris, E., Tri Iswanto, P., Pengaruh Natural dan Artificial Aging Pada Velg Bahan A356.0 Centrifugal Casting Dengan Variasi Putaran Terhadap Sifat Fisis dan Mekanis, Industrial Research Workshop and National Seminar (2012), pp. 87-94. 